\title{
ENCARNAÇÃO E A FICÇÃO ROMÂNTICA
}

\section{Encarnação and the romantic fiction}

\author{
Mario Luiz Frungillo*
}

\begin{abstract}
RESUMO
Publicado postumamente em 1877, Encarnação, de José de Alencar, tem recebido pouca atenção da crítica. Entretanto, esta obra, publicada quando o romance romântico já dava sinais de esgotamento, mostra diferenças consideráveis em relação à sua ficção anterior, dando mesmo a impressão de que, em alguns aspectos decisivos, representa uma revisão de valores, especialmente daqueles expressos nos romances urbanos do autor (e mesmo a sua inclusão nesse conjunto parece em momentos discutível). O romance, em suma, parece por vezes um pêndulo a balançar entre as convicções românticas de Alencar e o assédio do realismo já em seus começos no Brasil. E, assim como se relaciona de maneira problemática com a ficção que o antecede, também deixa dúvidas sobre a contribuição que Alencar, morto prematuramente, ainda poderia dar ao romance brasileiro.
\end{abstract}

Palavras-chave: romance brasileiro; José de Alencar; ficção romântica.

\begin{abstract}
Published posthumously in 1877, José de Alencar's last novel, Encarnação, has not received due attention from the critics. Nevertheless, this novel, published at a time when the romantic novel was showing signs of exhaustion, is really quite different from his earlier fiction: it leaves the impression that, in certain decisive ways, Alencar is taking a look at the fundamental values expressed in his urban novels, to the extent that the categorical inclusion of Encarnação among them seems to be highly debatable. It is as if the novel was balancing between
\end{abstract}

* Professor do Departamento de Teoria Literária do Instituto de Estudos da Linguagem (IEL) da Universidade Estadual de Campinas (UNICAMP). 
Alencar's romantic convictions and the demands of the new Realism, which at the time was in its initial phases in Brazil. The conflicted relationship of Encarnação with his earlier novels is suggestive as to what Alencar's contribution to the Brazilian novel might have been had he not died prematurely.

Key words: Brazilian novel; José de Alencar; romantic ficction.

Encarnação, romance de José de Alencar publicado postumamente em livro no ano de 1875 , costuma ser classificado entre as obras de ficção urbana do autor. E se há mesmo necessidade de uma classificação, sem dúvida essa é a mais adequada. Mas esse romance tem características particulares, que fazem dele um caso à parte dentro do conjunto das obras de ficção urbana do autor, pois parecem indicar que, com este livro, Alencar realizou uma revisão de alguns pontos de vista defendidos nas obras que o antecederam, por vezes mesmo com certa veemência.

Uma diferença cuja importância talvez não seja imediatamente perceptível é a da ação encapsulada da obra. O romance se passa quase todo no ambiente fechado de uma chácara situada no bairro de São Clemente, no Rio de Janeiro, distante da agitação do centro da cidade e dos lugares em que se desenrola a vida social. Nos romances anteriores esse tipo de ambiente tem geralmente uma função específica: é o lugar onde as personagens se despem das convenções sociais e revelam sua verdadeira personalidade: em Lucíola, Lúcia se revela como a conhecida figura romântica da prostituta pura num passeio pelo bairro da Glória, onde nascera e passara a infância. É numa chácara assim que Emília, de Diva, pela primeira vez abandona sua atitude desdenhosa e fria em sua relação com Augusto. Foi num subúrbio que Fernando Seixas, de Senhora, conheceu e se apaixonou por Aurélia, a quem abandonaria em busca de casamento mais vantajoso. É na casa simples de Dona Clementina que Amélia, de $A$ pata da gazela, começará a reconhecer em Leopoldo o homem digno de se casar com ela, o que levará à derrota das pretensões do leão da moda Horácio. Um ambiente retirado é também aquele que algumas das personagens escolherão para viver depois de vencidas as duras experiências que lhes marcaram as vidas. Assim é que os casais de Cinco minutos e de $A$ viuvinha vão viver em vizinhança numa casa localizada nas montanhas, fugindo dos ambientes em que sofreram suas provações. $O$ ambiente do qual todas essas personagens fogem é sempre o mesmo, é aquele em que pulsa a vida da sociedade carioca do novecentos, lugar de corrupção dos costumes, de abandono de valores mais antigos que o romancista parece querer reviver.

Contrastando o romance Encarnação com os anteriores, não podemos deixar de notar que neste o drama e as provações das personagens têm lugar justamente no ambiente que, nos outros romances, seria o lugar onde buscariam refúgio, ou onde alcançariam o conhecimento de si e dos outros. 
O que equivale a dizer que em Encarnação os conflitos começam onde, nos outros romances, cessam, e estão indissoluvelmente ligados à opção inicial das personagens por viverem ali.

Também o enredo, embora ainda gire em torno dos mesmos temas do amor e do casamento, apresenta algumas novidades: em primeiro lugar não se trata de uma relação desigual, da mescla de amor e interesse, ou melhor, do aviltamento do amor pelo interesse que forma o centro das intrigas de seus romances urbanos (com a exceção de Lucíola, que no entanto não se afasta tão decididamente do mesmo tema) e à qual o autor sempre dá um desfecho feliz. A felicidade, porém, só será alcançada depois que as personagens passarem por um processo de purificação, que é o verdadeiro motor dos enredos de Alencar. Esse processo de purificação possibilita ao autor combinar, na união dos casais, o amor imprescindível para sancioná-la com a necessidade de localizar socialmente suas personagens. Isso deu origem a eternas suspeitas quanto ao alcance da crítica social contida nesses romances, suspeitas essas que podem ser sintetizadas na observação de Antonio Candido, em Formação da literatura brasileira:

\begin{abstract}
Como bom romântico, [Alencar] procura sempre preservar a altivez e a pureza dos heróis, levando-os ao casamento rico por meio dum jogo hábil de amor, constância e inocência, que tornariam inoperante a acusação de interesse. Com efeito, no casamento de Augusto Amaral com Diva [sic] (Diva), no de Mário com Alice (O tronco do ipê), no de Miguel com Linda (Til), no de Leopoldo com Adelaide [sic] (A pata da gazela) - quem ousaria falar noutra coisa senão "o mais verdadeiro, o mais santo amor"? O certo, entretanto, é que os rapazes são todos pobres e as amadas muito ricas, filhas de grandes comerciantes e fazendeiros. A capacidade de observação levou o romancista a discernir o conflito da condição econômica e social com a virtude ou as leis da paixão; o seu idealismo artístico levou-o a atenuar o mais possível as consequências do conflito, inclusive no happy-end da forte história de conspurcação pelo dinheiro, que é Senhora. (CANDIDO, 1981, p.228)
\end{abstract}

De início, Encarnação, parece se encaminhar para uma trama semelhante. Amália, a protagonista, é uma moça que duvida da existência do amor, e não tem a menor intenção de se casar. Quando Teixeira, um amigo da família, se mostra surpreso com as opiniões da moça, o narrador assim explica a maneira pela qual ela se expressa:

O médico chegava da Europa, onde se tinha demorado quatro anos; e não sabia que a invasão do romance realista que nos vem 
de Paris, tem posto em moda certa gíria de cafés e bastidores, que algumas senhoras vão repetindo como linguagem de bom-tom sem consciência das enormidades que às vezes escondem tais ditos espirituosos. (ALENCAR, 1959, p.1239)

O alvo de Amália era Hermano, o morador da chácara vizinha. Ouvindo Teixeira gabar-lhe a fidelidade a Julieta, sua falecida esposa, Amália zombara da história que este lhe contara, observando que ele estava inventando uma Penélope do sexo masculino, coisa que nenhum poeta ainda se animara a fazer. Quando Teixeira objeta que isso fora feito por Garrett no seu Frei Luís de Sousa, Amália replica:

Esse fóssil conjugal é um monstro ideado por Garrett para complicar a situação das duas metades, que o aparecimento do primeiro marido veio separar. o drama está nessa separação, realmente incômoda, para quem não gosta de sair de seus hábitos. Assim o romeiro, bem longe de ser o herói, não passa de um pretexto, de um incidente, de um motivo. Faz aí o mesmo oficio de pai cruel, que não deixa a filha casar-se democraticamente com qualquer cidadão da rua. (ALENCAR, 1959, p.1238)

Tudo aqui parece indicar que teríamos, como sempre, um aprendizado romântico, desta vez, porém, tendo por protagonista uma personagem feminina. A diatribe contra a literatura romântica e o gosto pelo romance realista, explicitamente condenado pelo narrador, reforçam a impressão de que o plano do romance era traçar a descoberta não apenas do verdadeiro amor, mas dos valores verdadeiros por um caráter contaminado pelo espírito da época, aquele mesmo contra o qual se voltara toda a ficção anterior de Alencar, que em $A$ pata da gazela o qualificara de "materialista". Tal "materialismo" se manifestava tanto na busca de Fernando Seixas por um casamento rico quanto pela fixação fetichista de Horácio por um pé feminino cuja dona ele nem mesmo conhece. Corrobora ainda essa expectativa pela transformação final da personagem o fato de Amália, ao contrário da Emília, de Diva, ou mesmo da Aurélia Camargo, de Senhora, só se realizar plenamente em sociedade, de amar a luz dos salóes, sempre vista com desconfiança pelo romancista, por ser a luz que ilumina a falsidade desse estilo de vida:

Esta moça pertencia a uma variedade de mulher, que se pode bem classificar como o gênero rosa. São elegâncias que só florescem bem no clima ardente do baile, ao sol do gás. A luz é a alma de sua formosura. Na sombra desfalecem e murcham. (ALENCAR, 1959, p.1224-1225) 
Confirmando a expectativa criada por esse início, a conversa a respeito de Hermano chama para ele a atenção de Amália, que passa a observá-lo na chácara vizinha. Mais que isso, evoca-lhe a lembrança do idílio vivido por ele com Julieta naquela casa, e que ela observara quando ainda menina. Tem início, aparentemente, a transformação de Amália. Ela inevitavelmente se apaixonará por Hermano. Um dia, este é levado por Teixeira em visita à casa dos pais de Amália. Ele também, por sua vez, será seduzido por ela. Mas, ao contrário do que seria de esperar, não será por enxergar num sorriso toda sua alma, por reconhecer nela a mulher ideal. o que o atrai é surpreendê-la ao piano cantando a mesma ária de Lucia de Lamermoor que Julieta cantava na primeira vez em que a vira. Essa diferença é essencial: Amália não se revela por sua natureza, e sim por um ato social de menina bem educada. Como consequência dessa primeira impressão, Hermano se aproxima dela e, depois de alguma hesitação, a pede em casamento. Depois de casados, os dois vão viver na mesma casa em que Hermano vivera com Julieta. Mas o comportamento do moço é estranho e indica que algo perturba o relacionamento dos dois. Isso não se deve ao fato de ele não consumar a união, de nem sequer tocar a esposa. Casamentos cuja consumação se adia até ao final do romance não eram novidade na obra de Alencar, desde $A$ viuvinha e, principalmente, Senhora. Mas além de evitar a intimidade com Amália, ele também a impede de tocar o que quer que tenha um dia estado nas mãos de Julieta. Mantém intacto e trancado o quarto que fora da primeira esposa, não permitindo que ninguém entre nele. Por fim, Amália descobre que Hermano continua escravo da paixão por Julieta, a ponto de possuir duas estátuas de cera reproduzindo sua imagem escondidas na sua antiga alcova. Tal descoberta revela-lhe então a verdadeira natureza da paixão de seu marido pela morta:

O amor de Hermano era uma demência. Não fora uma mulher que ele havia adorado, e adorava ainda: mas um fantasma, um ente de sua imaginação. Esse ideal, ele o tinha encarnado em Julieta, desde o primeiro momento em que a vira. (ALENCAR, 1959, p.1305)

A prova disso é que as estátuas de cera não se parecem com o retrato da mulher, e sim com um quadro que ele vira no museu do Louvre, depois da morte dela, e com o qual identificara sua imagem. Isso explica por que Hermano não é capaz de responder a uma pergunta das mais simples: qual era a cor dos olhos de Julieta? Descobrimos também que desde o início ele associara a mulher a uma ideia preconcebida, e que confundira com amor a semelhança dela com essa ideia. Hermano repetira o mesmo engano com Amália, mas agora de uma maneira ainda mais doentia: ao 
vê-la cantando a ária da Lucia pensou que a moça poderia substituir sua primeira mulher. Colocou-a, ou acreditou poder colocá-la no lugar de sua primeira ilusão perdida.

Esse amor que não passa de demência, porém, não é senão exacerbação daquele amor ideal cantado por Alencar em todos os seus outros romances, amor capaz de aplainar todas as diferenças sociais entre os amantes, de justificar como happy-end o que a olhos mais céticos pareceria um mero caso de interesse. De interesse é que não se poderia falar aqui, pois Julieta não é herdeira rica, e aos olhos de todos é Hermano quem está fazendo um casamento desvantajoso. Além de não ser rica, Julieta também não é bela, pelo menos não o é exteriormente:

Como estátua a moça era um esboço imperfeito, ainda mesmo com as correções que aplica o molde de um traje elegante, ou a feliz disposição dos enfeites. [...]

Ao seu lado e conversando com ela, um homem de rigor estético poderia esquivar-se ao enlevo que infundia a suprema distinção dessa moça, e notar em suas feições e em seu talhe a ausência de beleza plástica.

Mas apartando-se dela e perdendo-a de vista, raro era o que não levava na fantasia um ideal suave e gracioso, que ofuscava a imagem das mais radiantes formosuras de salão. (ALENCAR, 1959, p.1228-1229)

Quando a encontrou pela primeira vez, Hermano não a viu como um "esboço imperfeito". Foi ao ouvi-la cantar a ária de Donizetti que ele primeiro reparou na moça, e foi assim que sentiu encontrar nela o ideal de amor que trazia dentro de si. o diálogo que travam quando do pedido de casamento parecia confirmá-lo e garantir um futuro pleno de felicidade:

- O casamento é uma fatalidade.

$[\ldots]$

- Meu marido há de pertencer-me de corpo e alma, como eu a ele,

e para sempre. É assim que entendo o casamento.

- Penso da mesma maneira.

- Para sempre é eternamente.

- Compreendi todo o seu pensamento, Julieta, e não imagina o meu júbilo por encontrar tão perfeita identidade de sentimentos na mulher a quem amo. Sempre acreditei que o casamento não deve ser uma simples união social, mas a formação da alma criadora e mãe, da alma perfeita, de que nós não somos senão as parcelas esparsas. Essa alma uma vez formada, só Deus a pode dividir e mutilar. (ALENCAR, 1959, p.1230) 
Não deveria espantar, aqui, que Hermano ignorasse a falta de formosura de Julieta (embora essa falta constituísse em si uma novidade) para enxergar-lhe somente a alma. Seu discurso não difere em nada do de Leopoldo, em $A$ pata da gazela, ao adivinhar a alma de Amélia em seu sorriso. Amélia era bela, mas Leopoldo não o percebeu da primeira vez em que a viu, assim como não saberia dizer a cor de seus cabelos. Além disso, durante muito tempo, por um equívoco só desfeito na noite de núpcias, ele acreditou que a amada escondia sob a barra dos vestidos uma deformidade física, e amou-a ainda assim. Hermano, por sua vez, embora tenha estranhado a cor negra dos cabelos da cantora da ária de Lucia, pois sempre imaginara que a personagem da ópera seria loura, quando indagado por Amália não soube sequer dizer a cor dos olhos da mulher a que se entregara para todo o sempre. Fica claro que seu enleio o fizera esquecer completamente a aparência desta que seria sua mulher ideal. Tal impressão vem a ser reforçada ainda pelo fato de que as estátuas de cera mandadas fazer por ele como forma de se consolar um pouco da ausência da esposa reproduzem a imagem de um quadro no qual pensou reencontrar a morta, e não as verdadeiras feições dela, que no entanto estão guardadas numa fotografia à qual poderia ter recorrido como modelo para aquelas estátuas.

Tudo isso transforma o casamento de Amália num pesadelo gótico. O marido vive para a morta, chega mesmo a sentar-se nos aposentos que pertenceram a ela e ler para as estátuas de cera como lera um dia para a esposa. A mulher que um dia exigira ser amada por ele para toda a eternidade se torna um fantasma a aprisionar-lhe a existência, e o diálogo travado no dia do pedido de casamento ganha a dimensão de um pacto sinistro com uma criatura que poderia ter saído de um conto de Edgar Allan Poe.

Assim, o romance sofre uma reviravolta. Quando parecia fazer uma crítica à negação do ideal de amor romântico por parte da heroína Amália para, depois disso, conduzi-la através de um processo de aprendizado rumo a esse mesmo ideal, o autor a joga no turbilhão de um pesadelo ultrarromântico. Este, porém, não é senão o ideal do Leopoldo de $A$ pata da gazela levado às últimas consequências. É aqui que Encarnação mostra a possibilidade de ser lido como uma revisão de pontos de vista anteriormente assumidos por Alencar a que nos referimos acima. Não se trata de dizer que ele tivesse, consciente ou inconscientemente, renegado seus livros anteriores. Podemos afirmar, contudo, que nesse seu último romance ele mostra o reverso deles para sondar o abismo que se poderia abrir de repente diante daqueles moços tão perdidamente enlevados pelas suas amadas a ponto de, nos momentos de extrema idealização, chegarem a privá-las de um corpo vivo para enxergar-lhes somente a alma. Encarnação representaria, nesse sentido, a busca de um limite, de um equilíbrio entre a consagração do amor 
verdadeiro e a necessidade de se ter uma existência real neste mundo, de viver em sociedade, enfim.

A partir do momento em que descobre o que realmente se passa com o marido, o amor de Amália deixa de significar o abandono de sua antiga objetividade, de seu ceticismo, atribuídos pelo autor à moda do romance realista importado da França, para se transformar numa consciente ação de salvamento de Hermano, ação que exigirá dela o emprego de toda sua força moral e psíquica. De início, Amália faz o possível para se tornar parecida com a antiga rival, veste-se como Julieta, procura imitar-lhe os gestos e a postura, como forma de conquistar o marido e arrancá-lo da possessão da outra. Tudo isso culmina na tentativa de Hermano de suicidar-se ateando fogo à casa. Mas é da destruição da cápsula em que vivera seu louco sonho de amor, com todas as lembranças que dele contém, que virá sua libertação. E aqui o romance completa seu movimento em direção inversa ao daqueles que o precederam: Hermano e Amália saem para o mundo, ao invés de fugirem dele. Voltam para o ambiente social, onde ambos encontravam sua plena realização antes de se isolarem para viver as vicissitudes de um idílio que quase se tornou fatal para ambos. A cena final, no entanto, ainda poderá causar estranheza e desconforto ao leitor: Depois de uma longa viagem, Amália e Hermano voltam para visitar as ruínas da chácara incendiada, trazendo consigo uma filha pequena, que tem o nome de Julieta. Seria sinal de uma recaída, uma justificação posterior da antiga paixão? É difícil responder, mas todo o desenrolar do romance não parece autorizar essa interpretação. Talvez se possa argumentar que a existência da filha serve para nos lembrar que a relação entre Hermano e Julieta era, além de doentia, condenada à esterilidade. Os dois de início não querem ter filhos para não terem que repartir seu amor com outras criaturas, e quando, mais tarde, ela engravida, um aborto espontâneo levará a criança e a mãe. Em Lucíola um desfecho semelhante apontava antes para a impossibilidade de Paulo se casar com uma cortesã, pelos limites impostos pela sociedade à redenção de uma mulher considerada decaída (moral com que o romancista estava, aliás, de acordo); do ponto de vista da construção da trama, portanto, da rendição do romancista romântico às leis da verossimilhança. Tal desfecho, além disso, possibilitava a realização do amor entre Paulo e Lúcia em outro plano (o que vem confirmado pelo início de Diva, em que reencontramos a personagem inteiramente dedicada ao culto da amada morta). Aqui, ao contrário, esse desfecho vem mostrar a impossibilidade de realização plena de um amor que só existe sob a forma de uma ilusão, de uma idealização que chega às raias da loucura, e que por isso mesmo se caracteriza por um egoísmo total, a ponto de renegar o mundo e pretender viver só para si mesmo. É possível que a escolha do nome também revele o reconhecimento 
de que gerar uma criança é a única maneira de dar vida a um ser humano sem atentar contra a natureza.

A leitura de Encarnação leva a muitas indagações a respeito da evolução de Alencar como romancista, e talvez mesmo dos destinos de nossa melhor ficção romântica. Sua extensa obra, seu conservadorismo, sua sisudez nos fazem com frequência esquecer que o escritor morreu com apenas 47 anos de idade. Entre a publicação de $A$ pata da gazela, talvez sua mais decidida defesa de uma concepção romântica de amor e casamento, e a de Encarnação, ocorrera a publicação dos primeiros romances e contos de Machado de Assis. Em especial $A$ mão e a luva, publicado dois anos depois de A pata da gazela, parecia escrito como resposta a esse romance de Alencar, por propor a não dissociação entre natureza e sociedade (visível na cena do reencontro entre Estêvão e Guiomar na chácara, onde ambos conversam mantendo estritamente os padrões de conduta social que, num romance de Alencar, seriam suspensos em favor de uma espontaneidade que lhes revelasse o verdadeiro caráter), pela não separação estrita entre amor e interesse, e também por apresentar um herói alternativo aos dois polos de atração da heroína Amélia: Luís Alves, o eleito de Guiomar, não é nem um sonhador romântico, nem um leão da moda: é um homem que "faz por si mesmo seu destino". Ocorrera ainda a publicação de Sonhos d'ouro e, principalmente, de Senhora, no qual Alencar se propusera a finalmente enfrentar de frente a questão do casamento por dinheiro, produzindo com isso o que é talvez seu melhor romance urbano, aquele em que ele mais se aproximou de Balzac, enquanto anteriormente parecera inspirar-se em Dumas Filho e em Octave Feulliet (sem, contudo, incorrer no filistinismo deste último).

Além das semelhanças com a literatura gótica - Eugênio Gomes vê em algumas cenas a inspiração dos Mistérios de Udolfo, de Anne Radcliff (GOMES, 1959, p.1219) -, Encarnação faz pensar também numa obra publicada quase trinta anos depois, e que deveria seu grande sucesso a um fato inesperado: trata-se de Gradiva, uma fantasia pompeiana, do alemão Wilhelm Jensen, publicada pela primeira vez em 1903, e que deve sua fama duradoura ao estudo que lhe dedicou Sigmund Freud. Sem querer forçar muito a semelhança entre obras publicadas em contextos diferentes por autores de mentalidades também diferentes, há alguns pontos em comum que podem ser destacados. Em sua pequena novela, Jensen narra a história de um arqueólogo, Norbert Hanold, que tem verdadeira fixação por um baixo-relevo romano no qual vem representada uma jovem caminhando. o motivo de sua fixação é o modo de andar da moça, que antes de deslocar o pé que está atrás o ergue até ficar numa posição quase perpendicular. Convencido de que o baixo-relevo se origina de Pompéia, o arqueólogo faz uma nova visita à cidade soterrada e lá, inesperadamente, encontra o objeto de sua fixação, a própria Gradiva rediviva. Ao final do terceiro encontro entre eles, desco- 
bre tratar-se na verdade de Zoe, sua antiga companheira de infância que, ao ver-se confundida com uma mulher morta dois milênios antes, assume esse papel como forma de trazer o amigo de volta à realidade. Com todas as diferenças que se podem apontar entre as duas obras, esse procedimento de cura de um homem da alienação por uma mulher que assume o papel da causa dessa alienação é uma semelhança notável entre as duas obras.

Podemos, assim, dizer que Encarnação sugere a necessidade de olhar-se para a ficção de Alencar como uma obra em progresso, cuja palavra final ainda não havia sido dada. Em parte por seu próprio amadurecimento como romancista, em parte, talvez, por conta de novas direções que começavam a se esboçar no romance brasileiro, especialmente com a publicação das primeiras obras de Machado de Assis, Alencar foi se afastando progressivamente de um tratamento idealizado das relações amorosas, afastamento de que Senhora é um dos produtos mais bem realizados, ainda que neste romance o desfecho ainda volte a confirmar suas tendências anteriores. Não se pode dizer que esse afastamento se fazia no sentido da aproximação de uma vertente de representação social no mesmo sentido em que caminhava a ficção em progresso de Machado de Assis. Nada em Encarnação permite uma afirmação assim drástica. Por outro lado, se a comparação com a Gradiva de Jensen é sustentável, podemos ver na ficção final de Alencar intuições de outras vertentes do romance ocidental surgidas no final do século XIX e início do XX, que inspirariam também as descobertas da nascente psicanálise, e que talvez não possam ser definidas sem maiores dificuldades através de uma simples referência ao rótulo dado por um movimento literário.

\section{REFERÊNCIAS}

ALENCAR, José de. Obra completa vol. 1. Romance urbano. Rio de Janeiro: Aguilar, 1959. CANDIDO, Antonio. Formação da literatura brasileira. 6. ed. Belo Horizonte: Itatiaia, 1981. GOMES, Eugênio. Nota preliminar. In: ALENCAR, José de. Obra completa vol. 1. Romance urbano. Rio de Janeiro: Aguilar, 1959.

JENSEN. Wilhelm. Gradiva - Uma fantasia pompeiana. Tradução de Ângela Melim. Rio de Janeiro: Jorge Zahar, 1997.

Submetido em: 07/04/2013

Aceito em: 30/06/2013 